\title{
Production of diaspores at the landscape level regulates local colonization: an experiment with a spore-dispersed moss
}

\author{
Niklas Lönnell, Bengt Gunnar Jonsson and Kristoffer Hylander \\ N. Lönnell (niklas.lonnell@su.se) and K. Hylander, Plant Ecology, Dept of Ecology, Environment and Plant Sciences, Stockholm Univ., \\ Lilla Frescati, SE-106 91 Stockholm, Sweden. - B. G. Jonsson, Dept of Natural Sciences, Mid Sweden Univ., SE-851 70 \\ Sundsvall, Sweden.
}

\begin{abstract}
Effective dispersal is crucial to species inhabiting transient substrates in order for them to be able to persist in a landscape. Bryophytes, pteridophytes, lichens and fungi all have wind-dispersed small diaspores and can be efficiently dispersed if their diaspores reach air masses above canopy height. However, empirical data on dispersal over landscape scales are scarce. We investigated how the colonization of an acrocarpous clay-inhabiting pioneer moss, Discelium nudum, varied between sites that differed in connectivity to potential dispersal sources at spatial scales from 1 to $20 \mathrm{~km}$ in a region in northern Sweden. We recorded the colonization on $\sim 25$ introduced clay heaps at each of 14 experimental sites some months after the dispersal period. The colonization rate ranged from $0-82 \%$ and had a statistically significant relationship with a proxy for potential habitats (amount of clay-dominated soil) in a buffer of $20 \mathrm{~km}$ radius surrounding the experimental sites (and also weakly with the amount of substrate in a $10 \mathrm{~km}$ buffer). There were no significant relationships between colonization rate and connectivity at smaller scales $(1$ and $5 \mathrm{~km})$. We made a rough estimate of the number of spores available for dispersal in a landscape, given the amount of clay-dominated soil, by recording the number of Discelium nudum colonies in two $25 \times 25 \mathrm{~km}$ landscapes. The estimated available spore numbers in the different $20 \mathrm{~km}$ buffers were of the same order of magnitude as the deposition densities at the experimental sites calculated from the colonization rates. The results suggest that the spores of species with scattered occurrences and small diaspores $(25 \mu \mathrm{m})$ in open landscapes can be deposited over extensive areas, at rates high enough to drive colonization patterns. This also implies that regional connectivity may be more important than local connectivity for these kinds of species.
\end{abstract}

One important factor in regulating population dynamics is dispersal (Clobert et al. 2012). In a continuous and stable environment, even a modest dispersal distance may suffice for both local population expansion and colonization of suitable new areas further away. Regular successful dispersal could be assumed to be less likely for species that live in dynamic and patchy landscapes with the difficulties accentuated by increasing spatial separation of patches and decreasing temporal windows for possible establishment (Johst et al. 2011, Baguette et al. 2013). However, the empirical basis for making accurate generalizations regarding regular dispersal distances is still limited for many organisms (Turchin 1998, Nathan et al. 2002). To help remedy this lack of empirical data, we explore spore dispersal of a bryophyte species in an experiment examining colonization patterns on a relatively large spatial scale (1-20 km) over a single dispersal season.

It is not possible to extrapolate results from studies of either active or passive dispersal by animals to passive dispersal by agents such as water and wind that many organisms (small animals, fungi and plants) rely on, since very different mechanisms are involved. Important aspects that need to be explored to understand wind dispersal are factors influencing both the release as well as the transport of the diaspores, including horizontal winds, thermal updrafts and other types of turbulence (Tackenberg et al. 2003, Skarpaas et al. 2006). It has also been suggested that mechanisms responsible for the deposition of a large numbers of diaspores closest to a source could be different from those resulting in the usually rare long-distance dispersal events (Nathan et al. 2008). It has been argued that species with minute diaspores should be ubiquitous (Fontaneto 2011). However, there is also evidence of clear dispersal limitation and, unfortunately, our knowledge of the dispersal ecology of the vast amounts of micro-organisms, fungi, lichen, bryophytes and ferns is actually still rather limited (Pharo and Zartman 2007, Fontaneto 2011). In addition, other organism groups such as orchids and other species groups with dust diaspores may disperse in similar ways. The size of the diaspores of these species groups ranges from $5 \mu \mathrm{m}$ (e.g. some fungal spores) to $1 \mathrm{~mm}$ (e.g. some dust seeds) and is one variable that may influence the ability and probability of transportation and deposition (Gregory 1973, Norros 2013). However, different authors have suggested different thresholds of diaspore size that might 
allow effective long-distance dispersal; from $20-40 \mu \mathrm{m}$ (Wilkinson et al. 2012) to 1-2 mm (Finlay 2002).

One obstacle in studies of dispersal is the limited possibility to track a single diaspore; indeed, as the size of the diaspores decreases the challenge of studying their dispersal increases. Therefore studies devoted to wind dispersal of microscopic diaspores (such as spores and pollen) are often limited to interpretations of the deposition, distribution patterns of established organisms, the genetic structure across an area, or modelling these properties. Studies of deposition patterns around a point source normally show that the density declines sharply over a few meters, but also reveal that a high percentage of the diaspores cannot be accounted for within this distance and would thus be available for deposition further away (Sundberg 2005). A decline in deposition density which levels out at around $50 \mathrm{~m}$ has been observed for both a fungus and a moss when distances up to $1 \mathrm{~km}$ were examined (Lönnell et al. 2012, Norros et al. 2012). Connectivity to potential spore sources at $3 \mathrm{~km}$ for wood-inhabiting polypore fungi (Edman et al. 2004a) or $200 \mathrm{~km}$ for Sphagnum peat mosses (Sundberg 2013) seem to explain deposition patterns better than smaller scale connectivity over one season or less. Large spatial scales $(>1 \mathrm{~km})$ have also been investigated in many indirect studies of bryophytes (involving the examination of genetic similarity or distribution patterns of established plants) but this also means that the temporal scale (50$300 \mathrm{yr}$ ) is extended in these studies. Such results suggest dispersal limitation for some bryophytes and fungi (Hedenås et al. 2003, Snäll et al. 2004a, b, Spagnuolo et al. 2007, Hutsemékers et al. 2010, 2013, Norros et al. 2012) but good dispersal capacity over a few decades to hundred years for other bryophytes and lichens (Cronberg 2002, Miller and McDaniel 2004, Sundberg et al. 2006, Hutsemékers et al. 2008, Hylander 2009, Gjerde et al. 2012, Szövényi et al. 2012).

Different conclusions about the dispersal capacity of species can be the result of both differences in methodology and the model species studied. That a single diaspore travels a long distance could, in the most favourable circumstances, be enough for the colonization of a distant island or even lead to a range expansion. However, a certain regularity of these dispersal events is needed to maintain a population at a landscape level, especially if the habitat or substrate is ephemeral. High mortality during transport and poor establishment are other factors that imply that high deposition densities are needed for successful dispersal (Norros 2013). Hence, not only differences in the release conditions, transport efficiency and deposition, but also number of diaspores produced, as well as establishment conditions are relevant in explaining species differences with respect to realized dispersal. The small size of the spores of, for example, fungi and bryophytes makes it possible for vast numbers to be produced compared with the number of diaspores produced in most vascular plants. The total spore production in a region depends on the regional frequency and local abundance of a species, as well as how prolific it is. Estimates of spore production per square metre colony per season for bryophytes vary by at least three orders of magnitude; from $44 \times 10^{6}$ to $38 \times 10^{9}$ (Söderström and Jonsson 1989).
The mean spore production for dominant species like Sphagnum spp. was estimated to be $16 \times 10^{6}$ spores per square metre of mire (Sundberg 2002). This is, however, nothing compared to some fungi that can produce huge numbers of spores, for example $0.5 \times 10^{6}$ (Heterobasidion annosum) to $21.9 \times 10^{6}$ (Trametes pubescens) spores per hour and square centimetre of hymenium (Rockett and Kramer 1974). Some estimates of the densities of spore deposition have also been undertaken for some species. For abundant taxa like Sphagnum peat mosses 60 000-240 000 spores per square metre and year have been recorded $40 \mathrm{~m}$ to $4 \mathrm{~km}$ from the nearest source (Sundberg 2013), but lower densities have been estimated for other taxa (Söderström and Jonsson 1989). However, the deposition densities that are needed for successful colonization depend on the germination conditions at the time of deposition and the intrinsic germination rate of spores of the focal species (Wiklund and Rydin 2004). One other factor that could influence dispersal is the release conditions, where species occurring in open landscapes should have a much higher probability of long-distance dispersal than those confined to dense forests (Nathan et al. 2008).

We used a unique study system in which it was possible to measure realized dispersal on an introduced specific substrate of an easily established, fast growing, and rather rare moss species, Discelium nudum. A previous experiment using the same study system showed that spores from a small patch source regularly disperse up to $50 \mathrm{~m}$ and rarely up to $600 \mathrm{~m}$ during one season (Lönnell et al. 2012). In light of this result we hypothesized that long distance dispersal is likely for this species even over short time scales (one season) and that it would be possible to quantify how the background spore deposition varies across landscapes that vary in amount of suitable habitats. We investigated whether the amount of suitable habitat (a proxy for potential spore production) at larger spatial scales regulates the rates of spore deposition at the local scale, by studying colonization rates on suitable introduced substrates used as spore traps in 14 landscapes differing in assumed spore production at various spatial scales $(1-20 \mathrm{~km})$.

\section{Methods}

\section{The study organism}

Discelium nudum is a pioneer acrocarpous moss distributed across the northern hemisphere in Europe, North America and Asia (Nyholm 1989); it grows on unstable banks along water courses as well as in more anthropogenically disturbed habitats (Duckett and Pressel 2003). In Sweden, it efficiently colonizes newly exposed neutral to acidic clay and is found in ditches and other habitats were the soil is regularly disturbed. However, the species seems to be rather rare in arable fields. Discelium nudum seems to be a good competitor when colonizing newly disturbed clay surfaces. However, due to its small size, it needs regular disturbance to remain on a site since other bryophytes and vascular plants soon establish and take over. The species grows most abundantly on glacial clay and performs somewhat worse 
on silt and postglacial clay. It disperses its spores during a short period in spring (April-May) and completes its life cycle in one year. An extensive protonema develops from the spore, and from this a dense stand, normally of many very small shoots, develops (Fig. 1). The sporophyte grows from the fertilized archegonium; it has a $1-3 \mathrm{~cm}$ long seta and a capsule containing around 15000 spores (Lönnell et al. 2012). The spores have a diameter of around 25 (range 21.8-30.1) $\mu \mathrm{m}$ (Boros et al. 1993).

\section{The study area}

We conducted the experiment in an area in northern Sweden within a radius of $80 \mathrm{~km}$ of the city of Umea along the coast in the county of Västerbotten $\left(63^{\circ}-64^{\circ} \mathrm{N}, 19^{\circ}-20^{\circ} \mathrm{E}\right)$ (Fig. 2). The landscape is a mosaic of forests, clear cuts, mires, and agricultural land. Discelium nudum has scattered occurrences in the region and can become locally abundant along ditches on newly exposed clay.

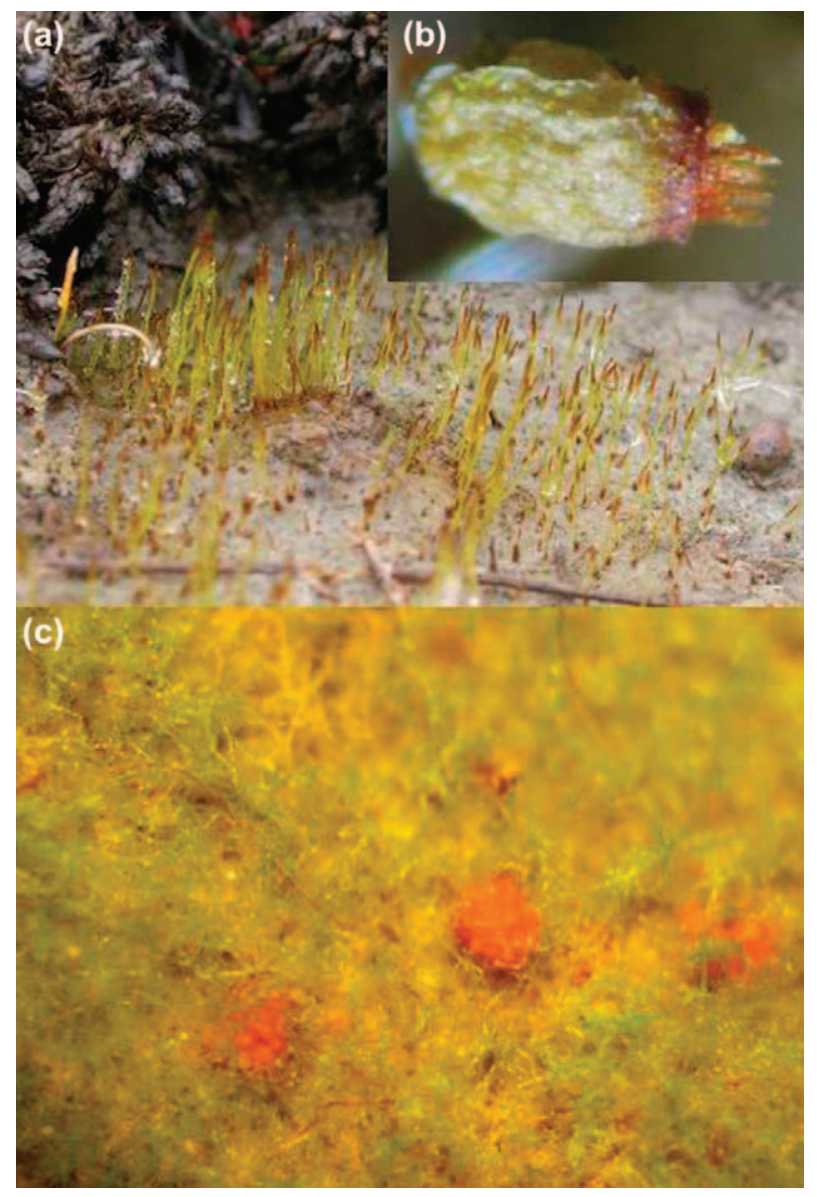

Figure 1. The study species Discelium nudum: (a) immature sporophytes which usually grow rather densely. The setae will reach a length of $1-3 \mathrm{~cm}$ when they are mature. (b) The mature capsule contains around 15000 spores with a diameter of around $25 \mu \mathrm{m}$. (c) Several shoots develop from the extensive protonema. The photograph shows male shoots with the orange antheridia surrounded by green protonema.

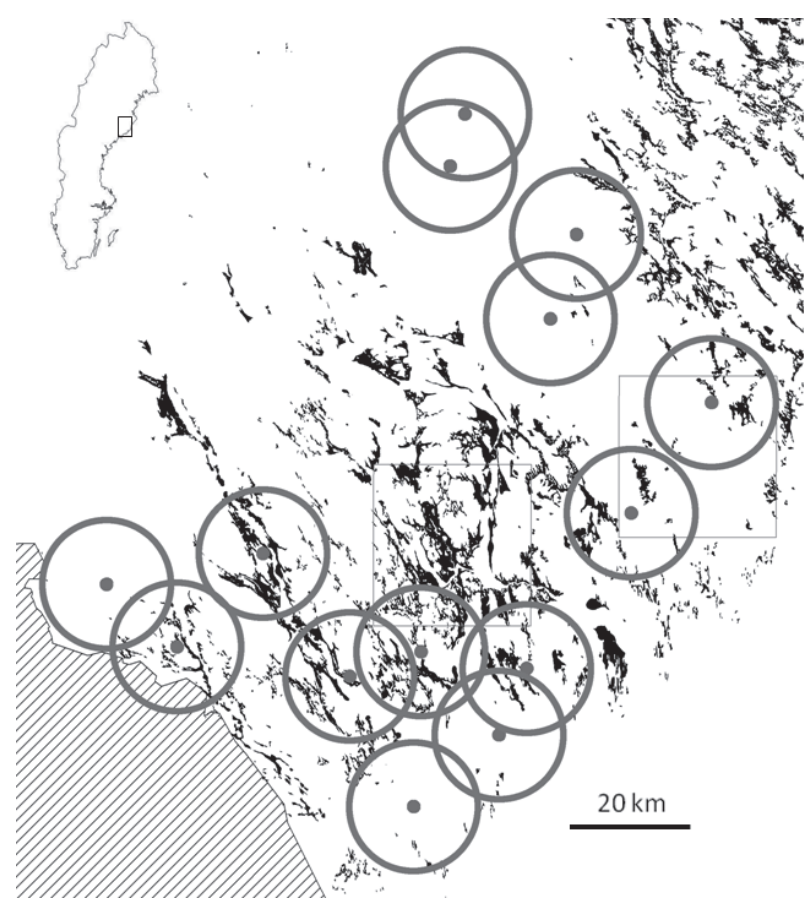

Figure 2. Location of the 14 experimental sites (grey dots) surrounded by $10 \mathrm{~km}$ buffers (grey circles). Black areas denote clay-dominated soils (data from the Swedish Geological Survey; see Methods). No detailed digital soil cover data were available for the southwestern corner of the landscape (dashed area). Grey squares delimit the two areas where the densities of natural occurrences of the moss in the region were assessed.

\section{Study design and collection of colonization data}

Across this landscape we searched for suitable experimental sites on open mires; previously, we have found that these are good places to follow colonization of experimental clay heaps because they remain moist over the entire season and thus are suitable for germination and growth of Discelium nudum. Moreover, the location ensures that the immediate surroundings of each experimental site is unsuitable for Discelium nudum. The criteria for choosing the mires included presence of certain peat mosses (Sphagnum spp.), which would keep the clay moist and not allow it to sink during the months it was out in the field. Moreover, we tried to stratify the sites to ensure a large variation in the amount of clay-dominated soils (on which potential parent populations could occur) in the surrounding landscape (in a 1,5 , and $10 \mathrm{~km}$ radius). Out of 100 mires visited in the area, we finally chose 14 experimental sites distributed across the focal landscape which fullfilled our criteria (Fig. 2).

We retrieved clay for the experiment from a depth of 2-3 m below the ground with an excavator (6 May 2010) and stored it in plastic boxes with lids. At least 20 heaps with clay (approximately $1 \mathrm{dm}^{2}$ ) were placed on the peat moss carpet at each of the 14 field sites on 19-21 October 2010. The location of the clay within each mire was a tradeoff between finding a sufficiently humid location during the growing season and avoiding the possibility that the clay would sink and become covered by the surrounding Sphagnum shoots. Based on previous experience we placed 
the clay in transition zones between the dry tussocks (e.g. with Sphagnum fuscum) and the wettest hollows (often with Sphagnum section Cuspidata or section Sphagnum). We recorded the number of colonized heaps at each experimental site 12-13 October 2011, four months after the dispersal period (May 2011) of the species in the landscape.

\section{Connectivity measures}

We measured the habitat connectivity as the proportion of clay-dominated soils (assuming a correlation with possible spore sources) in a radius of $1,5,10$ and $20 \mathrm{~km}$ around each experimental site as well as from surveys of the species (and thus actual spore sources) in the surrounding $1 \mathrm{~km}$ from each experimental site.

From the digital vector layers from the regional quaternary database (available from Geological Survey of Sweden, $<$ www.sgu.se $>$ and corresponding to original maps of the quaternary deposits at a scale of 1:100 000 in series Ak from the Geological Survey of Sweden) the areas of the following soil classes were measured and cumulative figures obtained: glacial clay, glacial silt, clay, clay-silt, temporarily inundated clay-silt, postglacial clay, silt, and flood-plain deposits. In three cases, the buffer area of $10 \mathrm{~km}$ and/or $20 \mathrm{~km}$ radius extended outside the area covered by the digital map. In those cases we digitalized and measured the additional area of clay, fine silt and coarse silt from the printed map Quaternary deposits of Västernorrland county at a scale of 1:200 000 (Lundqvist 1986).

We obtained the other estimate of connectivity by surveying for Discelium nudum within a $1 \mathrm{~km}$ radius of the experimental sites. We visited all suitable habitats and recorded the number and position of occurrences of Discelium nudum during the period 24-30 May 2011. One occurrence was defined as having a maximum length of $100 \mathrm{~m}$, to account for situations where the species was growing along linear elements such as roads or ditches.

\section{Estimation of spore production at the landscape scale}

To estimate the likely production of spores of Discelium nudum in the $20 \mathrm{~km}$ buffer areas we used data from performed survey conducted in 2009. Two landscapes $(25 \times 25 \mathrm{~km})$, one with a high proportion of clay-dominated soils $(25 \%)$ and one with a low proportion of clay-dominated soils $(4 \%)$ were chosen in the focal region, approximately $10-40 \mathrm{~km}$ apart (grey squares in Fig. 2). Over a period of three days we visited disturbed sites on what were shown as clay-dominated soils on the geological map and estimated the cover of protonemata of allcolonies of Discelium nudum that we found. By relating the mean protonema area to the total area of clay-dominated soil we were able to estimate how much Discelium nudum was present in different landscapes. Because we estimated the spore production per square metre of protonema to be $150 \times 10^{6}$ (assuming the number of spores per capsule to be 15000 (Lönnell et al. 2012) and a mean number of sporophytes of 10000 per square metre of protonema), we were able to calculate two estimates (based on the two landscapes) of the total spore production in the neighbouring landscapes of all experimental sites. Assuming that the spores produced were dispersed in such a way that they were evenly distributed over the whole area, we could then calculate two different values of possible deposition densities for each experimental site.

\section{Estimation of number of established spores}

The proportion of colonized clay heaps is related to the number of spores deposited. We used the ratio of uncolonized heaps to make a rough estimate of the mean number of spores resulting in colonizations of the other heaps by assuming a Poisson distribution of the deposited spores (according to equation, for details see Lönnell et al. 2012). Thus, we were able to estimate the density of spores that had resulted in the colonizations at each experimental site.

$$
\lambda=-\ln ((n-k) / n)
$$

where: $\lambda=$ the mean number of spores per heap (over the heaps at one sampling station); $n=$ the number of heaps at one sampling station; $k=$ the number of colonized heaps at one sampling station.

\section{Data analysis}

We investigated the relationship between the two measures of connectivity i.e. the presence/absence of Discelium nudum in a $1 \mathrm{~km}$ buffer around the experimental site as a function of the extent of clay-dominated soils in that area by means of a logistic regression. We tested the relationship between the colonization rate on the heaps and the presence/absence of extant Discelium nudum colonies within the $1 \mathrm{~km}$ buffer with an analysis of variance (ANOVA). We tested the relationship between the colonization rate on the heaps and the proportion of clay-dominated soils within the four buffers $(1,5,10,20 \mathrm{~km})$ and the number of occurrences of Discelium nudum using a generalized linear model with a quasi-binomial distribution (because of overdispersion). We $\log _{10}$-transformed the explanatory variables (number of occurrences of Discelium nudum or the proportion of clay-dominated soils) in all these analyses (with the addition of 0.01 to the original number) to improve normality and reduce the overdispersion. In the case of the largest scales $(10$ and $20 \mathrm{~km}$ ), we took into account possible spatial autocorrelation in an additional analysis by including four clusters (Supplementary material Appendix 1, Fig. A1) with a lot of overlap (especially in the $20 \mathrm{~km}$ case) as a random factor (and individual sites as a random factor to account for the overdispersion) in a mixed effect model (lme4-package) (Bates et al. 2013).

The data were analysed using the statistical software $R$ 2.15.2 (R. Core Team). The species names of mosses follow Hill et al. (2006).

\section{Results}

The colonization rates of the moss Discelium nudum on the clay heaps varied from 0 to $82 \%$ among the 14 sites.

The proportion of clay-dominated soils measured in buffers with a radius of 1 to $20 \mathrm{~km}$ varied from 0 to 0.48 , 


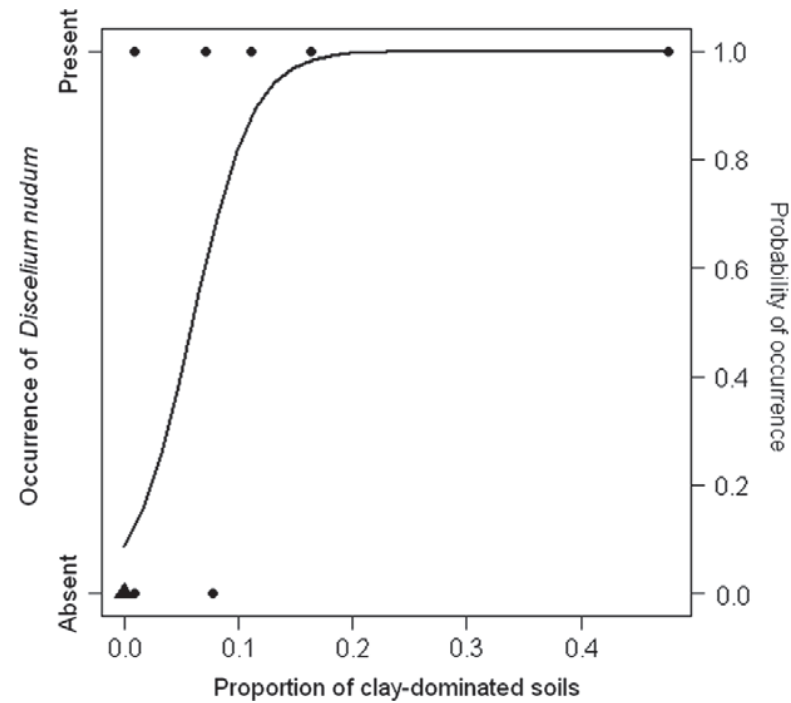

Figure 3. Presence/absence data of Discelium nudum within buffers of $1 \mathrm{~km}$ radius around the experimental sites, plotted together with the probability function of occurrence (from a logistic regression) given the proportion of clay-dominated soils within the same areas. The triangle represents seven data points.

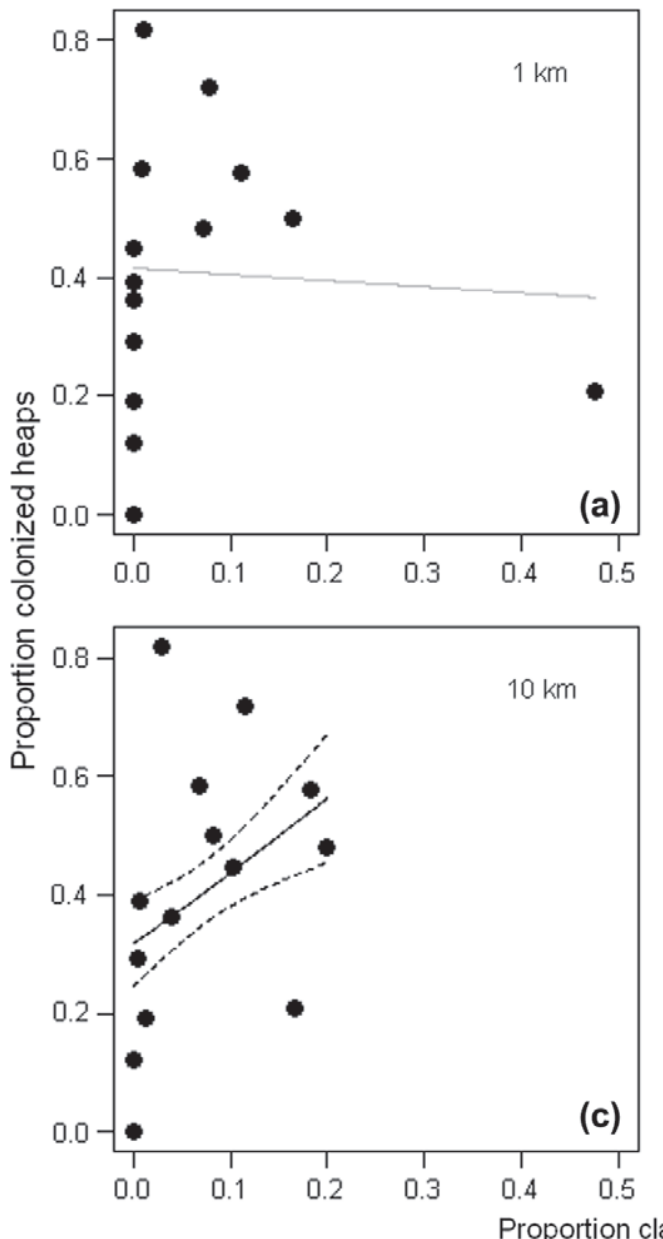

with the highest values in some of the $1 \mathrm{~km}$ buffers. The inventory of the species in the $1 \mathrm{~km}$ buffers showed that it was absent from nine buffers and varied in number of occurrences from one to nine in the others. The proportion of clay-dominated soils in an area with a radius of $1 \mathrm{~km}$ surrounding the experimental site was positively related to the probability of Discelium nudum being present in that area (logistic regression, $p=0.0026$, Fig. 3). Hence, we can conclude that the extent of clay-dominated soils is a good proxy for the probability of Discelium nudum being present in the landscape.

The variation in colonization rates on the introduced heaps did not correlate with either the extent of clay-dominated soils in the $1 \mathrm{~km}$ buffers ( $\mathrm{p}=0.31$, Fig. $4 \mathrm{a}$ ), or the presence of Discelium nudum in that area either measured as number of occurrences $(p=0.51)$ or analysed in the form of presence or absence data $(p=0.54)$. This was also true if the two variables (the extent of clay-dominated soils and number of occurrences) were tested in combination.

However, the relationship between the colonization rate and the extent of clay-dominated soils in the surrounding landscape became stronger with increasing spatial scale, and was highly significant at a buffer size of $20 \mathrm{~km}$ radius
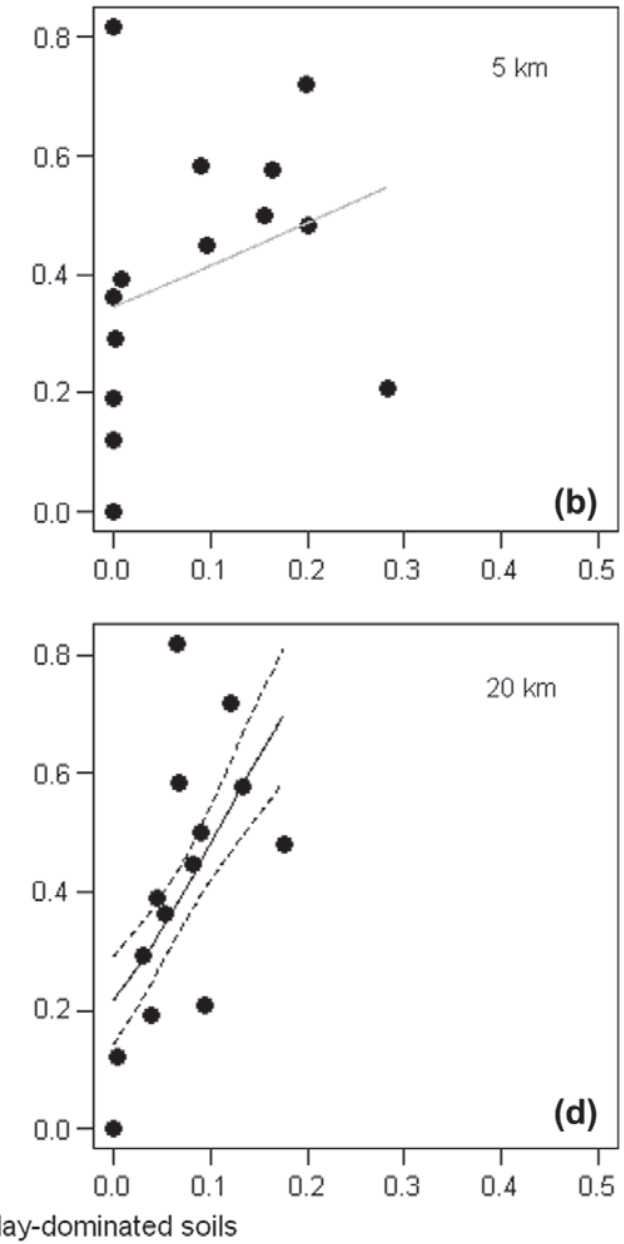

Figure 4. Proportion of heaps colonized by Discelium nudum at the 14 experimental sites as a function of the proportion of clay-dominated soils in buffers of 1, 5, 10 and $20 \mathrm{~km}$ radius surrounding the sites. The solid lines denote the predicted values from binominal models and the dashed lines the confidence intervals (for the significant models with the explanatory variable $\log _{10}$-transformed). 
( $p=0.007$, Fig. $4 d$ ) and weakly so with a $10 \mathrm{~km}$ buffer $(\mathrm{p}=0.043$, Fig. 4c) (for model statistics see Supplementary material Appendix 1, Table A1). The results did not change when possible spatial autocorrelation was taken into account (Supplementary material Appendix 1, Table A2).

The variation between the 14 sites in estimated spore production during one season in the $20 \mathrm{~km}$ buffers ranged from 32 to 7614 million or from 205 to 48308 million spores depending on which of the landscape estimations was used (Methods). If all these spores were evenly distributed over the whole area of the $20 \mathrm{~km}$ buffers, the result would be a variation in deposition of $0.1-0.6$ spores per square meter in the buffers with the smallest area of clay-dominated soils, to 24-154 spores per square meter in the buffers with the largest area of suitable substrates. The estimated depositions based on actual colonizations of the heaps were 0 to 54 spores per square meter among the sites.

\section{Discussion}

We found that the influence of the proportion of claydominated soils on the colonization ratio became stronger with increasing scale examined, being strongest for the largest investigated buffers, i.e. those with a $20 \mathrm{~km}$ radius. Surprisingly, there was no effect at the smallest scale $(1 \mathrm{~km})$, even when the actual number of occurrences of the species in the surrounding area was used as the explanatory variable. This implies that the species is a good disperser and that there is a large regional spore source that influences colonization more than the contribution from the nearest populations. Initially, this appears to be counterintuitive since we know that there is a steep decline in deposition of diaspores (also shown for spores) from a point source (Söderström and Jonsson 1989, Bullock and Clarke 2000, Roads and Longton 2003, Sundberg 2005, Lönnell et al. 2012). However, over somewhat longer time scales, establishment on islands of abundant moss species like Sphagnum spp. and Hylocomium splendens seem to depend on mainland sources rather than the closest ones (Cronberg 2002, Sundberg et al. 2006). Moreover, in a recent study of deposition patterns of Sphagnum spores, it was found that a connectivity of $200 \mathrm{~km}$ provided the best explanation for the deposition (Sundberg 2013). However, as noted in the introduction several other studies on genetic structure and occurrence patterns suggest more restricted dispersal at a landscape scale (Snäll et al. 2004a, Hutsemékers et al. 2013, Korpelainen et al. 2013, Rosengren et al. 2013). In light of the investigations suggesting good dispersal capacities, our result should not be altogether surprising, and it is even possible that we could have found a stronger relationship between colonization rates and extent of clay-dominated soils if we had implemented a design that allowed us to investigate even larger scales. However, our result contradict some other studies showing dispersal limitation over rather short distances, which we hypothesize to be mainly due to differences among species in for example life history traits.

Given the observed pattern in our results, with a stronger relationship with extent of suitable substrate at increasing distances, we do not think that we would have obtained a better fit using some kind of connectivity function taking into account every patch with Discelium nudum in the surrounding landscapes (even if such data had been available). It could be that a significant proportion of the spores of this species are transported up to air layers above canopy height and, if so, they can travel both short and long distances due to stochastic wind events. This is supported by some other studies of abundant mosses (Sphagnum) showing that they seem to be more dependent on mainland sources than local sources on other islands (Sundberg et al. 2006, Szövényi et al. 2012). On the other hand, the use of buffers at larger scales involves many dispersal and wind events over a larger area and this produces a reliable estimates of connectivity. In addition, for organisms which could be assumed to display a clear declining dispersal kernel over longer distances, a buffer may perform better than a connectivity function (Ranius et al. 2010). As shown by Moilanen and Nieminen (2002), the nearest neighbour connectivity measure usually performs worse than using either a buffer or some more elaborate connectivity function. When choosing between a negative exponential function and a buffer, it may be a matter of taste and the nature of the studied organism although the incidence function seems to produce a slightly better fit in some studies on insects (Moilanen and Nieminen 2002). We used the area of surrounding clay-dominated soils to estimate connectivity. However, this measure is probably sometimes quite an unreliable estimate of the area which can support Discelium nudum (especially in the smaller buffers) since the proportion of bare clay can vary greatly in an area and it is not possible to know the exact extent without a thorough inventory in the particular year. Moreover, the soil maps for the studied area do not distinguish between clay and silt or between glacial and postglacial clay, which decreases the resolution of the measure. Despite these shortcomings, our results indicate that the buffer is an acceptable proxy for the extent of suitable and colonized patches on a large scale.

Discelium nudum is rather rare on a national scale, but the populations seem to be able to reach considerable sizes on suitable substrates in the river valleys along the coast of northern Sweden. Considering that the species invests much in reproduction and given that a proportion of the spores are transported up into the air masses above canopy height, it seems likely that a pattern involving a regional spore source that is well distributed over the area can arise. In our experiment, the minimum distance to a population was $100-200 \mathrm{~m}$, which is beyond those $40-50 \mathrm{~m}$ where the sharp decline in the probability function levels out from a point source (Lönnell et al. 2012, Norros et al. 2012). We therefore suggest that if a suitable patch is located outside the immediate vicinity of a spore source where a substantial proportion of the spores remain, those spores that are deposited there may be spores that have made it up into the air thanks to horizontal winds, thermal upheaval or turbulent winds and may have travelled considerable distances (cf. discussion in Hylander 2009, Lönnell et al. 2012).

Our attempt to roughly estimate the number of available dispersed spores in the $20 \mathrm{~km}$ buffers showed that this amount could result in a deposition rate of $0.1-154$ spores per square metre depending on the cover of clay-dominated soils in the different buffers (assuming that the spores were evenly distributed over the area). Interestingly, these 
estimates were in the same order of magnitude as the deposition rates of 0 to 54 spores per square metre estimated from the colonized heaps. Having said that, we need to take into account the fact that not all spores germinate, that a high proportion of the spores are normally deposited near the source (Lönnell et al. 2012), that the estimation of the total spore source is very coarse, with multiplication in several steps, and that there is a possibility of some contamination on the heaps. It is, even so, intriguing and thought provoking that the figures are so similar. Our estimates of spore production at a landscape scale, although rough, suggest that there can be a very large number of spores available for colonization; this was also verified by our experiment. A comparison between the measured deposition of spores (27-74 spores per square meter) at the experimental sites where Discelium nudum was found, and the deposition $50-600 \mathrm{~m}$ from a translocated source (2-6 spores per square meter, Lönnell et al. 2012) also suggest that it not likely that only the nearby sources contributed to the deposition and subsequent colonization observed in this experiment.

The rough estimate of $150 \times 10^{6}$ spores produced per square meter of Discelium nudum colony is somewhat higher than estimates for some other bryophytes $-16 \times 10^{6}$ (Sphagnum spp.) and $44 \times 10^{6}$ (Ptilidium pulcherrimum) - but well below the highest $38 \times 10^{9}$ (Tortula muralis) (Söderström and Jonsson 1989, Sundberg 2002). However, one should bear in mind that Discelium nudum allocates a large proportion of its resources to reproduction and that the sporophyte is the dominant stadium of the moss, since the gametophyte mostly consists of a protonema and very tiny shoots with only a few leaves. More abundant and widespread bryophytes with lower levels of spore production as well as rarer, more prolific species could probably reach similar levels of production as Discelium nudum on a landscape scale.

Transport of a diaspore to a suitable site is not the same thing as a successful dispersal event, since establishment could represent a bottleneck for many species. In our experiment we provided an optimal substrate for Discelium nudum, thus supporting a high establishment rate. Moreover, Discelium nudum is able to cover the bare clay rapidly because it has an extensive protonema, which gives it an advantage over other species directly after disturbance. Other species may not be as fortunate and what may seem like a strong dispersal limitation may, in fact, reflect an establishment limitation, if for example the early colonizers monopolize the resource and hinder the latecomers from establishing and reproducing (Waters et al. 2013). Another factor that could result in poor realized dispersal is high mortality of spores during transport. Moreover, very specific conditions may be required for germination, resulting in a narrow window of opportunity for establishment, which seems to be the case for many epiphytes (Wiklund and Rydin 2004). This could also be true for many fungi that live on dead wood, where deposition densities of $4700 \mathrm{~m}^{-2} 24 \mathrm{~h}^{-1}$ may be needed for establishment (Edman et al. 2004b). An extreme example of highly specific conditions for successful establishment is the need to encounter a symbiont, for example less than $1 \%$ of the dust seeds of orchids (which need a fungus to germinate and develop to a viable individual) may survive to form a mature plant (Batty et al. 2001). Taking into account the fact that rather high deposition rates are needed for these species, it would not suffice for a single diaspore to arrive at a site, but rather that a high enough concentration of diaspores is present. Compared to many of these examples, Discelium nudum has better prospects of becoming established, and this may help to explain the observed pattern of high establishment ratios on the experimental heaps.

\section{Conclusions}

This study suggests that some spore-dispersed species with diaspores as large as $25 \mu \mathrm{m}$ can regularly travel long distances even during a single dispersal event (one season). The rates were so high that it is likely that regional spore availability is a major driver of local population dynamics of this species. One should not, however, generalize this finding to all species, as there are studies that have revealed dispersal limitation for other bryophytes even over longer temporal scales (Löbel et al. 2006, Hutsemékers et al. 2010). For regional spore dispersal to be the probable driver of local dynamics, a species must invest much in diaspore production, be common enough so that the diaspore source becomes large enough to build up a regional spore rain and not be greatly establishment-limited. More studies on species differing in life history strategies, traits related to dispersal and ecologies are needed to obtain a nuanced picture of the circumstances under which species with spores can disperse regularly and effectively over long distances.

Acknowledgement - We are grateful to the following people who have helped in the field and/or with preparatory work: Emil Johansson, Mats Dynesius, Andreas Karlsson Tiselius, Jean Baptiste Jouffray, Sofi Lundbäck. This research was funded by a grant from FORMAS [to KH].

\section{References}

Baguette, M. et al. 2013. Individual dispersal, landscape connectivity and ecological networks. - Biol. Rev. 88: 310-326.

Bates, D. et al. 2013. lme4: linear mixed-effects models using S4 classes. - R package ver. 0.999999-2, < http://CRAN.R-project. org $/$ package $=$ lme $4>$.

Batty, A. L. et al. 2001. Constraints to symbiotic germination of terrestrial orchid seed in a mediterranean bushland. - New Phytol. 152: 511-520.

Boros, Á. et al. 1993. An atlas of recent European bryophyte spores. - Scientia Publishing.

Bullock, J. and Clarke, R. 2000. Long distance seed dispersal by wind: measuring and modelling the tail of the curve. - Oecologia 124: 506-521.

Clobert, J. et al. (eds) 2012. Dispersal ecology and evolution. - Oxford Univ. Press.

Cronberg, N. 2002. Colonization dynamics of the clonal moss Hylocomium splendens on islands in a Baltic land uplift area: reproduction, genet distribution and genetic variation. - J. Ecol. 90: 925-935.

Duckett, J. and Pressel, S. 2003. Studies of protonemal morphogenesis in mosses. IX. Discelium nudum: exquisite pioneer of unstable clay banks. - J. Bryol. 25: 241-245.

Edman, M. et al. 2004a. Spore deposition of wood-decaying fungi: importance of landscape composition. - Ecography 27: 103-111. 
Edman, M. et al. 2004b. Local dispersal sources strongly affect colonization patterns of wood-decaying fungi on spruce logs. - Ecol. Appl. 14: 893-901.

Finlay, B. J. 2002. Global dispersal of free-living microbial eukaryote species. - Science 296: 1061-1063.

Fontaneto, D. (ed.) 2011. Biogeography of microscopic organisms: is everything small everywhere? - Cambridge Univ. Press.

Gjerde, I. et al. 2012. Community assembly in epiphytic lichens in early stages of colonization. - Ecology 93: 749-759.

Gregory, P. H. 1973. The microbiology of the atmosphere, 2nd ed. - Leonard Hill.

Hedenås, H. et al. 2003. Spatial distribution of epiphytes on Populus tremula in relation to dispersal mode. - J. Veg. Sci. 14: 233-242.

Hill, M. O. et al. 2006. An annotated checklist of the mosses of Europe and Macaronesia. - J. Bryol. 28: 198-267.

Hutsemékers, V. et al. 2008. How far and how fast do bryophytes travel at the landscape scale? - Divers. Distrib. 14: 483-492.

Hutsemékers, V. et al. 2010. Macroecological patterns of genetic structure and diversity in the aquatic moss Platyhypnidium riparioides. - New Phytol. 185: 852-864.

Hutsemékers, V. et al. 2013. Does water facilitate gene flow in spore-producing plants? Insights from the fine-scale genetic structure of the aquatic moss Rhynchostegium riparioides (Brachytheciaceae). - Aquat. Bot. 108: 1-6.

Hylander, K. 2009. No increase in colonization rate of boreal bryophytes close to propagule sources. - Ecology 90: $160-169$.

Johst, K. et al. 2011. Biodiversity conservation in dynamic landscapes: trade-offs between number, connectivity and turnover of habitat patches. - J. Appl. Ecol. 48: 1227-1235.

Korpelainen, H. et al. 2013. Spatial genetic structure of aquatic bryophytes in a connected lake system. - Plant Biol. 15: 514-521.

Löbel, S. et al. 2006. Metapopulation processes in epiphytes inferred from patterns of regional distribution and local abundance in fragmented forest landscapes. - J. Ecol. 94: 856-868.

Lönnell, N. et al. 2012. The fate of the missing spores - patterns of realized dispersal beyond the closest vicinity of a sporulating moss. - PLoS One 7: e41987.

Lundqvist, J. 1986. Jordartskarta över Västernorrlands län och förutvarande Fjällsjö k:n: Quaternary deposits of Västernorrland county. - National Library of Sweden Sveriges geologiska undersökning.

Miller, N. G. and McDaniel, S. F. 2004. Bryophyte dispersal inferred from colonization of an introduced substratum on Whiteface Mountain, New York. - Am. J. Bot. 91: 1173-1182.

Moilanen, A. and Nieminen, M. 2002. Simple connectivity measures in spatial ecology. - Ecology 83: 1131-1145.

Nathan, R. et al. 2002. Mechanisms of long-distance dispersal of seeds by wind. - Nature 418: 409-413.

Nathan, R. et al. 2008. Mechanisms of long-distance seed dispersal. - Trends Ecol. Evol. 23: 638-647.

Norros, V. 2013. Measuring and modelling airborne dispersal in wood decay fungi. - PhD thesis, LUOVA, Finnish School of Wildlife Biology and Conservation and Management, Dept of Biosciences Faculty of Biological and Environmental Sciences, Univ. of Helsinki.

Norros, V. et al. 2012. Dispersal may limit the occurrence of specialist wood decay fungi already at small spatial scales. - Oikos 121: 121: 961-974.

Supplementary material (Appendix ECOG-00530 at $<$ www.oikosoffice.lu.se/appendix $>$ ). Appendix 1 .
Nyholm, E. 1989. Illustrated flora of Nordic mosses. Fasc. 2, Pottiaceae - Splachnaceae - Schistostegaceae. - The Nordic Bryological Society.

Pharo, E. and Zartman, C. 2007. Bryophytes in a changing landscape: the hierarchical effects of habitat fragmentation on ecological and evolutionary processes. - Biol. Conserv. 135: $315-325$.

Ranius, T. et al. 2010. A comparison of patch connectivity measures using data on invertebrates in hollow oaks. - Ecography 33: 971-978.

Roads, E. and Longton, R. 2003. Reproductive biology and population studies in two annual shuttle mosses. - J. Hattori Bot. Lab. 93: 305-318.

Rockett, T. R. and Kramer, C. L. 1974. Periodicity and total spore production by lignicolous basidiomycetes. - Mycologia 66: 817.

Rosengren, F. et al. 2013. Genetic variation in the moss Homalothecium lutescens in relation to habitat age and structure. - Botany 91: 431-441.

Skarpaas, O. et al. 2006. Environmental variability and the initiation of dispersal: turbulence strongly increases seed release. - Proc. R. Soc. B 273: 751-756.

Snäll, T. et al. 2004a. Distribution pattern of the epiphyte Neckera pennata on three spatial scales - importance of past landscape structure, connectivity and local conditions. - Ecography 27: 757-766.

Snäll, T. et al. 2004b. Spatial genetic structure in two congeneric epiphytes with different dispersal strategies analysed by three different methods. - Mol. Ecol. 13: 2109-2119.

Söderström, L. and Jonsson, B. G. 1989. Spatial pattern and dispersal in the leafy hepatic Ptilidium pulcherrimum. - J. Bryol. 15: 793-802.

Spagnuolo, V. et al. 2007. Molecular biodiversity in the moss Leptodon smithii (Neckeraceae) in relation to habitat disturbance and fragmentation. - J. Plant. Res. 120: 595-604.

Sundberg, S. 2002. Sporophyte production and spore dispersal phenology in Sphagnum: the importance of summer moisture and patch characteristics. - Can. J. Bot. 80: 543-556.

Sundberg, S. 2005. Larger capsules enhance short-range spore dispersal in Sphagnum, but what happens further away? - Oikos 108: 115-124.

Sundberg, S. 2013. Spore rain in relation to regional sources and beyond. - Ecography 36: 364-373.

Sundberg, S. et al. 2006. Colonization of Sphagnum on land uplift islands in the Baltic Sea: time, area, distance and life history. - J. Biogeogr. 33: 1479-1491.

Szövényi, P. et al. 2012. Long-distance dispersal and genetic structure of natural populations: an assessment of the inverse isolation hypothesis in peat mosses. - Mol. Ecol. 21: 5461-5472.

Tackenberg, O. et al. 2003. Assessment of wind dispersal potential in plant species. - Ecol. Monogr. 73: 191-205.

Turchin, P. 1998. Quantitative analysis of movement: measuring and modeling population redistribution in animals and plants. - Sinauer Associates.

Waters, J. M. et al. 2013. Founder takes all: density-dependent processes structure biodiversity. - Trends Ecol. Evol. 28: 78-85.

Wiklund, K. and Rydin, H. 2004. Ecophysiological constraints on spore establishment in bryophytes. - Funct. Ecol. 18: 907-913.

Wilkinson, D. M. et al. 2012. Modelling the effect of size on the aerial dispersal of microorganisms. - J. Biogeogr. 39: 89-97. 